Provided for non-commercial research and education use. Not for reproduction, distribution or commercial use.

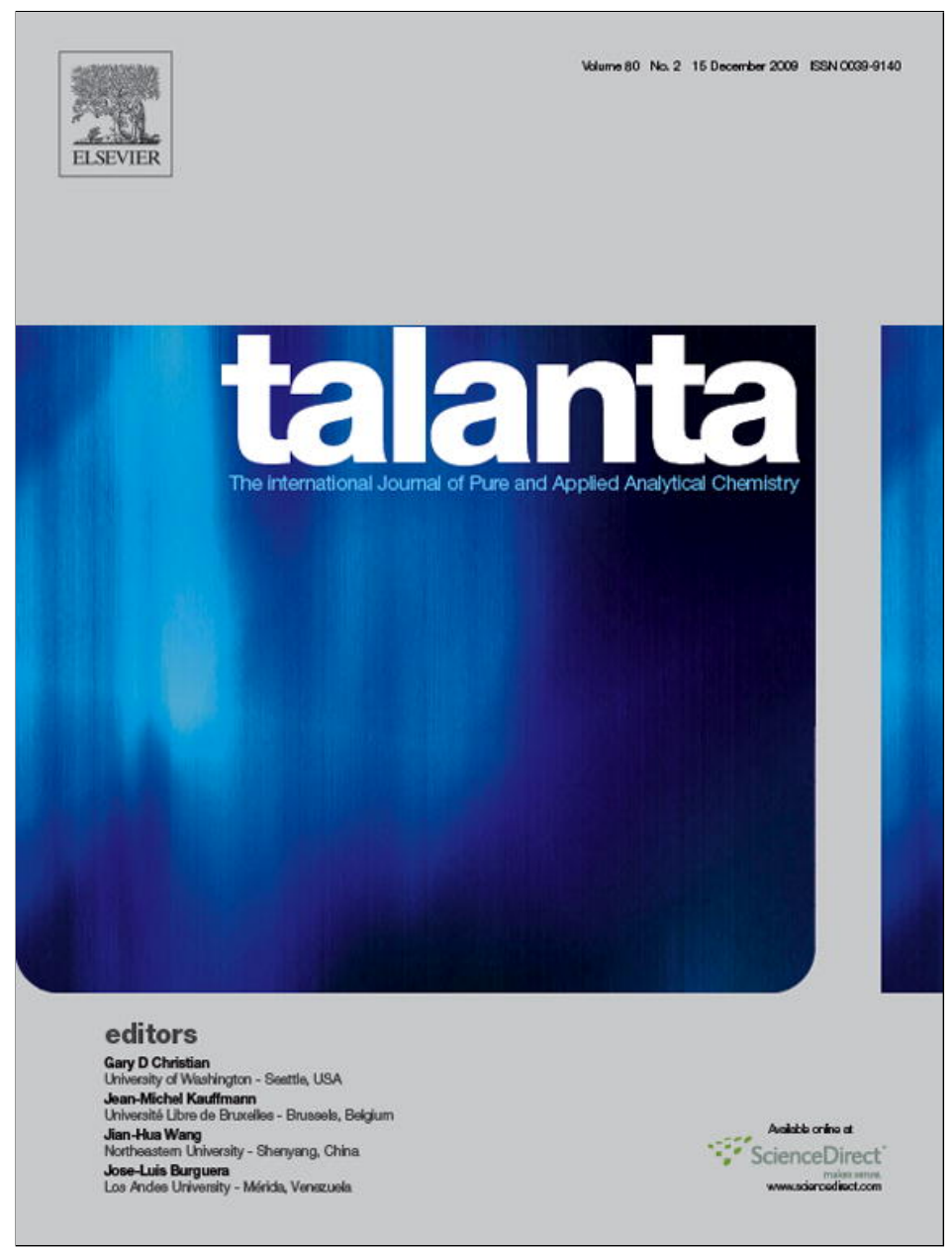

This article appeared in a journal published by Elsevier. The attached copy is furnished to the author for internal non-commercial research and education use, including for instruction at the authors institution and sharing with colleagues.

Other uses, including reproduction and distribution, or selling or licensing copies, or posting to personal, institutional or third party websites are prohibited.

In most cases authors are permitted to post their version of the article (e.g. in Word or Tex form) to their personal website or institutional repository. Authors requiring further information regarding Elsevier's archiving and manuscript policies are encouraged to visit:

http://www.elsevier.com/copyright 


\title{
Potentialities of two solventless extraction approaches-Stir bar sorptive extraction and headspace solid-phase microextraction for determination of higher alcohol acetates, isoamyl esters and ethyl esters in wines
}

\author{
R. Perestrelo ${ }^{\mathrm{a}, \mathrm{b}}$, J.M.F. Nogueira ${ }^{\mathrm{b}, \mathrm{c}}$, J.S. Câmara ${ }^{\mathrm{a}, *}$ \\ a Centro de Química da Madeira, Universidade da Madeira, Departamento de Química, Campus Universitário da Penteada, 9000-390 Funchal, Portugal \\ b Universidade de Lisboa, Faculdade de Ciências, Departamento de Química e Bioquímica, Campo Grande Ed. C8, 1749-016 Lisboa, Portugal \\ ' Universidade de Lisboa, Faculdade de Ciências, Centro de Química e Bioquímica, Campo Grande Ed. C8, 1749-016 Lisboa, Portugal
}

\section{A R T I C L E I N F O}

\section{Article history:}

Received 14 April 2009

Received in revised form 15 July 2009

Accepted 20 July 2009

Available online 28 July 2009

\section{Keywords:}

Solid-phase microextraction

Stir bar sorptive extraction

Higher alcohol acetates

Isoamyl esters

Ethyl esters

Wine

Gas chromatography-quadrupole mass

spectrometry

\begin{abstract}
A B S T R A C T
A stir bar sorptive extraction with liquid desorption followed by large volume injection coupled to gas chromatography-quadrupole mass spectrometry (SBSE-LD/LVI-GC-qMS) was evaluated for the simultaneous determination of higher alcohol acetates (HAA), isoamyl esters (IsoE) and ethyl esters (EE) of fatty acids. The method performance was assessed and compared with other solventless technique, the solidphase microextraction (SPME) in headspace mode (HS). For both techniques, influential experimental parameters were optimised to provide sensitive and robust methods. The SBSE-LD/LVI methodology was previously optimised in terms of extraction time, influence of ethanol in the matrix, liquid desorption (LD) conditions and instrumental settings. Higher extraction efficiency was obtained using 60 min of extraction time, $10 \%$ ethanol content, $n$-pentane as desorption solvent, 15 min for the back-extraction period, $10 \mathrm{~mL} \mathrm{~min}^{-1}$ for the solvent vent flow rate and $10^{\circ} \mathrm{C}$ for the inlet temperature. For HS-SPME, the fibre coated with 50/30 $\mu \mathrm{m}$ divinylbenzene/carboxen/polydimethylsiloxane (DVB/CAR/PDMS) afforded highest extraction efficiency, providing the best sensitivity for the target volatiles, particularly when the samples were extracted at $25^{\circ} \mathrm{C}$ for $60 \mathrm{~min}$ under continuous stirring in the presence of sodium chloride $(10 \%(\mathrm{w} / \mathrm{v}))$. Both methodologies showed good linearity over the concentration range tested, with correlation coefficients higher than 0.984 for HS-SPME and 0.982 for SBES-LD approach, for all analytes. A good reproducibility was attained and low detection limits were achieved using both SBSELD $\left(0.03-28.96 \mu \mathrm{g} \mathrm{L}^{-1}\right)$ and HS-SPME $\left(0.02-20.29 \mu \mathrm{g} \mathrm{L}^{-1}\right)$ methodologies. The quantification limits for SBSE-LD approach ranging from 0.11 to $96.56 \mu \mathrm{g} \mathrm{L}^{-}$and from 0.06 to $67.63 \mu \mathrm{g} \mathrm{L}^{-1}$ for HS-SPME. Using the HS-SPME approach an average recovery of about 70\% was obtained whilst by using SBSE-LD obtained average recovery were close to $80 \%$. The analytical and procedural advantages and disadvantages of these two methods have been compared.

Both analytical methods were used to determine the HAA, IsoE and EE fatty acids content in "Terras Madeirenses" table wines. A total of 16 esters were identified and quantified from the wine extracts by HS-SPME whereas by SBSE-LD technique were found 25 esters which include 2 higher alcohol acetates, 4 isoamyl esters and 19 ethyl esters of fatty acids. Generally SBSE-LD provided higher sensitivity with decreased analysis time.
\end{abstract}

(C) 2009 Elsevier B.V. All rights reserved.

\section{Introduction}

Aroma compounds are important in wine as they contribute to the quality of the final product, hence to the consumer acceptance [1]. The wine volatile fraction can be composed by over 800 different compounds [1,2], but only several tens of which can be odour active [3] and must be considered for differentiation purposes. These compounds belong to different chemical

\footnotetext{
* Corresponding author. Tel.: +351 291705112; fax: +351291705149.

E-mail address: jsc@uma.pt (J.S. Câmara).
}

families, including higher alcohols, ethyl esters, fatty acids, acetates, isoamyl esters, carbonyls, sulphurs, furanics, monoterpenols, $\mathrm{C}_{13^{-}}$ norisoprenoids and volatile phenols, presenting different polarities, volatilities and moreover, are found in a wide range of concentrations from $\mathrm{ng} \mathrm{L}^{-1}$ to $\mathrm{mg} \mathrm{L}^{-1}[4,5]$. They proceed from four major sources, like (i) grapes; (ii) processing of the grapes (namely crushing, pressing, etc.) by chemical, enzymatic-chemical and thermal reaction in grape must; (iii) fermentation process, and (iv) chemical reactions during maturation of wine (wood, commonly oak). An important part of wine aroma arises during the alcoholic fermentation of grape sugars by the wine yeast, which produces ethanol, carbon dioxide and a number of by-products including 
higher alcohols and esters [6], whose formation is closely related to the particular yeast species involved. Acetates, such as ethyl acetate, hexyl acetate, isoamyl acetate and 2-phenylethyl acetate are recognised as very important flavour compounds in wine and other grape-derived alcoholic beverages. In general, these volatile compounds have a pleasant odour and a low perception threshold, which allows the assumption that they contributed to the wine aroma even present in small concentrations. The main esters in commercial wines used to be ethyl and 3-methylbuthyl esters of short-chain fatty acids [7].

The analysis of volatile and semi-volatile organic compounds that contribute to wine aroma has been carried out following different methodologies, such as liquid-liquid extraction $[4,8,9]$, purge and cold trapping extraction [10], simultaneous distillation-extraction [11], supercritical fluid extraction [12], solid-phase extraction [13] and ultrasound extraction [14]. However, most of these approaches present several disadvantages, including expensive equipment requirements, significant amounts of environmentally unfriendly solvents, multiple handling steps that increase error, and the need for a concentration step to achieve detectable levels. Nowadays, there are available solventless alternatives to these classical methodologies, which may overcome all those disadvantages such as the well-known solid-phase microextraction (SPME), developed by Pawliszyn et al. $[15,16]$ and more recently, stir bar sorptive extraction (SBSE) proposed by Baltussen et al. [17]. The latter methodology uses the Twister ${ }^{\mathrm{TM}}$, a glass stir bar onto which is bonded a polydimethylsiloxane (PDMS) phase, in quantities far in excess of those found on SPME fibres [18]. The SBSE extraction takes place when the aqueous sample begins to be stirred by the bar during a period of time until the volatile or semivolatile compounds reach the equilibrium and after enrichment, are thermally desorbed (TD) followed by gas chromatography analysis usually coupled to mass spectrometry (GC-MS) [19-21]. These sorptive extraction approaches showed great advantages when compared with other conventional enrichment methodologies, since eliminate the use of toxic organic solvents, allow the determination of a large number of analytes with low limits of detection and good linear dynamic ranges, combine extraction, concentration and instrumental analysis into a single step, require no or little manipulation/sample preparation, reduce substantially the analysis time, are simple and faster methods, cover a wide range of sampling techniques, including field, in situ and air matrices and can be performed by immersing the polymeric coatings into sample medium or in the headspace (HS). In general, the accepted disadvantages are relatively lot-to-lot variations, sensitivity against organic solvents and the limited range of commercially available specific stationary phases $[22,23]$.

In the last years, SBSE have becoming more accepted since present remarkable sensitivity and accuracy than SPME in particular, during trace analysis of complex matrices such as wine samples $[18,24,25]$. For instance, it was already demonstrated that SBSETD is an analytical technique much more powerful than HS-SPME, which allowed higher ability for profiling trace and ultra-trace compounds for Madeira wine characterisation [18]. Nevertheless, the TD systems are expensive devices and many times, are not the best option to analyse particular thermolabile constituents, due to the very high desorption temperature requirements with possible occurrence of artefacts. Moreover, the TD mode does not offer the opportunity of multiple injections, which is an important issue in many studies during validation purposes. More recently, we proved that SBSE-LD is a remarkable alternative presenting interesting features to overcome these limitations $[20,21,26]$. In this approach, the analytes are trapped followed by removal through back-extraction with a small volume (typically microliters) of a convenient organic solvent prior to GC-MS analysis. Furthermore, if we combine large volume injection (LVI) to enhance sensitivity with suitable desorp- tion solvents under optimised conditions [19], volatile compounds can be easily analysed in wine matrices, as was reported lately [27]. Although HS-SPME [28,29] and SBSE-LD methodologies can be easily applied in any laboratory since they do not need special instrumental requirements, both procedures were never compared in terms of analytical advantages, selectivity and sensitivity.

The purpose of the present work is to compare the performance of two solventless sorptive extraction approaches: HS-SPME/GC-MS versus SBSE-LD/LVI-GC-MS, for the determination of volatile compounds in wines, using HAA, IsoAE and EE as model compounds. The optimisation, validation and application of both methodologies, as well as the advantages observed are fully discussed using commercial wines from different grape varieties produced in Madeira Island.

\section{Experimental}

\subsection{Reagents and standards}

Methanol $(\mathrm{MeOH})$, acetonitrile $(\mathrm{ACN})$ and acetone purchased from Fluka (Buchs, Switzerland) were of HPLC grade. 2-Phenylethyl acetate, ethanol, diethyl ether and $n$-pentane were supplied from Riedel-de Haën (Barcelona, Spain). Isoamyl acetate, 2-propanol, ethyl hexanoate, octanoate and ethyl salicylate and clear glass vials were purchased from Sigma-Aldrich Química S.A. (Madrid, Spain). Ethyl decanoate, dodecanoate, cinnamate, benzoate, lactate, 2 -furoate and ethyl butyrate were supplied from Acros (Geel, Belgium). Isoamyl hexanoate and isoamyl octanoate were obtained from SAFC (Steinheim, Germany). Pure water was obtained from a Milli-Q purification system (Millipore, Bedfords, MA, USA). Sodium hydroxide $(\mathrm{NaOH}, 98 \%)$ and sodium chloride $(\mathrm{NaCl}, 98.5 \%)$ were purchased from Panreac (Barcelone, Spain). The SPME fibres, the manual SPME holder and the PTFE coated-silicone caps, were purchased from Supelco (Bellefonte, PA, USA). The glass vials $(30 \mathrm{ml})$ were obtained from Macherey-Nagel, (Düren, Germany). The manual crimper was obtained from Agilent Technologies (Little Falls, DE, USA) and the Variomag Multipoint komet agitation plate from Thermo Fisher Scientific Inc. (Waltham, MA, USA). The stir bars (Twister; Gerstel, Müllheim a/d Ruhr; Germany) containing PDMS ( $0.5 \mathrm{~mm}$ film thickness, $10 \mathrm{~mm}$ in length) with a volume of $24 \mu \mathrm{L}$ were used. Ultrasonic equipment, Branson 3510, was purchased from Branson Ultrasonic Corporation (Danbury, CT, USA).

Individual stock standard solutions of each target compound were prepared by weight in ethanol. A global stock standard solution, containing all the analytes under study, was prepared in a synthetic wine matrix $\left(120 \mathrm{ml} \mathrm{L}^{-1}\right.$ of ethanol, $5 \mathrm{~g} \mathrm{~L}^{-1}$ of tartaric acid and $\mathrm{pH} 3.3$ adjusted with $\mathrm{NaOH}$ ). Working solutions were prepared by diluting different amounts of the global standard solution in a synthetic wine. All solutions were stored at $4{ }^{\circ} \mathrm{C}$. For calibration purposes five different levels of concentration, covered the concentration ranges expected in wines, were prepared. Three replicates of each level were analysed. The average and the relative standard deviation (R.S.D.) were calculated.

\subsection{Wine samples}

All varieties used were Vitis vinifera $\mathrm{L}$. species. The most important and most representative commercial "Terras Madeirenses" wines from Madeira Island (Portugal), produced according to standard procedures, were selected. The grapes were crushed, de-stemmed, racked and pressed. The musts were fermented in stainless-steel containers at $22^{\circ} \mathrm{C}$ with spontaneous yeast. The white wines, Enxurros (ENX) and Palmeira (PAL) of 2005 vintage and Quinta do Moledo Reserva (QMR) of 2004 vintage, were produced using Verdelho \& Arnsburguer, Verdelho \& Bual \& Arns- 
Table 1

Calibration and sensitivity data of the 14 examined compounds obtained with HS-SPME and SBSE-LD methodologies.

\begin{tabular}{|c|c|c|c|c|c|c|c|c|c|c|}
\hline \multirow[t]{2}{*}{$\operatorname{Ion}(m / z)$} & \multirow[t]{2}{*}{ Kovats index } & \multirow[t]{2}{*}{ Volatile compounds } & \multicolumn{2}{|c|}{ Concentration range $\left(\mu \mathrm{g} \mathrm{L}^{-1}\right)$} & \multicolumn{2}{|l|}{$R^{2}$} & \multicolumn{2}{|c|}{ Slope $\left(\mu \mathrm{gL}^{-1}\right)$} & \multicolumn{2}{|c|}{ Intercept $\left(\mu \mathrm{g} \mathrm{L}^{-1}\right)$} \\
\hline & & & SPME & SBSE & SPME & SBSE & SPME & SBSE & SPME & SBSE \\
\hline \multicolumn{11}{|c|}{ Higher alcohol acetates } \\
\hline 43 & 1008 & Hexyl acetate & $34.84-696.80$ & $5.81-929.07$ & 0.995 & 0.999 & $3.24 \times 10^{6}$ & $7.15 \times 10^{7}$ & $-1.25 \times 10^{5}$ & $6.37 \times 10^{5}$ \\
\hline 104 & 1238 & 2-Phenylethyl acetate & $2.00-120.00$ & $1.37-549.33$ & 0.997 & 0.993 & $1.18 \times 10^{7}$ & $1.81 \times 10^{7}$ & $-4.60 \times 10^{4}$ & $-5.86 \times 10^{5}$ \\
\hline \multicolumn{11}{|c|}{ Isoamyl esters } \\
\hline 43 & 925 & Isomayl acetate & $120.00-4800.00$ & $40.00-2666.67$ & 0.996 & 0.997 & $3.15 \times 10^{6}$ & $1.88 \times 10^{7}$ & $-6.14 \times 10^{5}$ & $1.15 \times 10^{6}$ \\
\hline 70 & 1233 & Isoamyl hexanoate & $1.00-40.00$ & $0.67-20.00$ & 0.985 & 0.998 & $6.88 \times 10^{8}$ & $1.81 \times 10^{8}$ & $-2.21 \times 10^{6}$ & $-2.58 \times 10^{5}$ \\
\hline 70 & 1431 & Isoamyl octanoate & $1.00-40.00$ & $0.67-20.00$ & 0.998 & 0.992 & $2.18 \times 10^{9}$ & $1.38 \times 10^{8}$ & $-3.04 \times 10^{6}$ & $5.61 \times 10^{4}$ \\
\hline \multicolumn{11}{|c|}{ Ethyl esters } \\
\hline 71 & 778 & Ethyl butanoate & $40.00-1600.00$ & - & 0.984 & - & $8.33 \times 10^{5}$ & - & $5.50 \times 10^{3}$ & - \\
\hline 88 & 1006 & Ethyl hexanoate & $20.00-1200.00$ & $0.66-666.67$ & 0.998 & 0.997 & $1.36 \times 10^{7}$ & $1.65 \times 10^{7}$ & $-4.70 \times 10^{5}$ & $9.67 \times 10^{4}$ \\
\hline 95 & 1038 & Ethyl 2-furoate & $222.88-4457.60$ & $37.23-1489.33$ & 0.995 & 0.998 & $7.15 \times 10^{6}$ & $3.92 \times 10^{6}$ & $-2.61 \times 10^{6}$ & $-1.90 \times 10^{5}$ \\
\hline 105 & 1091 & Ethyl benzoate & $40.00-2000.00$ & $26.67-2666.67$ & 0.993 & 0.995 & $6.03 \times 10^{6}$ & $4.59 \times 10^{7}$ & $-5.25 \times 10^{5}$ & $-7.84 \times 10^{5}$ \\
\hline 88 & 1205 & Ethyl octanoate & $20.00-2400.00$ & $0.67-1178.33$ & 0.998 & 0.997 & $1.04 \times 10^{8}$ & $1.12 \times 10^{8}$ & $-3.58 \times 10^{4}$ & $8.90 \times 10^{5}$ \\
\hline 120 & 1240 & Ethyl salicylate & $20.00-600.00$ & $153.19-1477.14$ & 0.990 & 0.982 & $7.93 \times 10^{7}$ & $4.02 \times 10^{7}$ & $-2.00 \times 10^{6}$ & $3.43 \times 10^{6}$ \\
\hline 88 & 1410 & Ethyl decanoate & $20.00-800.00$ & $0.67-666.67$ & 0.991 & 0.997 & $9.30 \times 10^{7}$ & $2.94 \times 10^{8}$ & $2.24 \times 10^{6}$ & $-2.74 \times 10^{6}$ \\
\hline 131 & 1441 & Ethyl cinnamate & $200.00-2400.00$ & $0.67-666.67$ & 0.990 & 0.989 & $7.58 \times 10^{6}$ & $1.14 \times 10^{8}$ & $8.39 \times 10^{4}$ & $-3.56 \times 10^{6}$ \\
\hline 88 & 1607 & Ethyl dodecanoate & $9.00-300.00$ & $0.81-80.06$ & 0.995 & 0.994 & $1.49 \times 10^{8}$ & $1.72 \times 10^{8}$ & $-1.30 \times 10^{6}$ & $2.13 \times 10^{5}$ \\
\hline
\end{tabular}

$R^{2}$ : determination coefficient; (-) not determined by SBSE (solvent delay higher than its retention time).

burguer and Verdelho grapes, respectively. Therefore, Verdelho grapes were the main composition of white wines studied. The Colombo (COL) red wine of 2004 vintage was produced using Tinta Negra Mole grape variety. The grapes were harvested at optimum maturity evaluated by indices of sugar and acid content. All samples were taken from bottled wines $(750 \mathrm{ml})$ and stored at $-28^{\circ} \mathrm{C}$ until analysis. In all cases, analysis was performed in triplicate and the values were averaged. For the optimisation of HS-SPME extraction methods, Enxurros (ENX) young white wine from 2005 harvest was used.

\subsection{Extraction procedure}

\subsubsection{SPME assays}

Six different coating fibres: $75 \mu \mathrm{m}$ carboxen-poly(dimethylsiloxane) (CAR/PDMS), $65 \mu \mathrm{m}$ carbowax-divinylbenzene (CW/ DVB), 50/30 $\mu$ m divinylbenzene-carboxen-poly(dimethylsiloxane) (DVB/CAR/PDMS), $100 \mu \mathrm{m}$ poly(dimethylsiloxane) (PDMS), $85 \mu \mathrm{m}$ polyacrylate (PA) and $65 \mu \mathrm{m}$ poly(dimethylsiloxane)-divinylbenzene (PDMS/DVB) were assessed to evaluate their performance for the study of HAA, IsoAE and EE in wines. The fibres were conditioned following the manufacturer instructions by inserting them into the GC injector port. Before the first daily analysis the fibres were conditioned for $6 \mathrm{~min}$ at $240^{\circ} \mathrm{C}$ in the GC injector. A blank test was performed to check possible carry-over. Besides the fibre type, some other SPME parameters that influence the extraction process were optimised, namely extraction time $(5,15,30,60$ and $75 \mathrm{~min})$, temperature $\left(25,30,40\right.$ and $\left.60^{\circ} \mathrm{C}\right)$, ionic strength $(0,10,20$ and $30 \%$ $\mathrm{NaCl}(\mathrm{w} / \mathrm{v}))$ and matrix effects (12, 15, 17 and $19 \%(\mathrm{v} / \mathrm{v})$ of ethanol). For each HS-SPME assay, aliquots of $10 \mathrm{~mL}$ of wines were placed into a $20 \mathrm{~mL}$ clear glass vial, to which $10 \%(\mathrm{w} / \mathrm{v})$ of $\mathrm{NaCl}$ was added, and hermetically sealed with a PTFE coated-silicone cap, after addition of a small stirring bar. The extractions were carried out at wine $\mathrm{pH}$ (3.3). The vial was placed in a thermostat block on a stirrer. The SPME fibre was inserted into the HS at the sampling time during the sampling extraction time. All solutions were stirred at constant speed $(800 \mathrm{rpm})$. After sampling, the fibre was retracted, removed from the sample vial and manually introduced into the GC injection port. Each assay was performed in triplicate.

\subsubsection{SBSE assays}

Each wine sample was introduced into a glass vial $(30 \mathrm{~mL})$; a stir bar with PDMS coating film ( $0.5 \mathrm{~mm}$ thick; $10 \mathrm{~mm}$ long, $24 \mu \mathrm{L})$ was immersed, and the vial was closed with a seal (aluminium seals with PTFE septa) using a manual crimper. Assays were performed in a 15th agitation point plate at room temperature $\left(25^{\circ} \mathrm{C}\right)$, using an extraction time of $60 \mathrm{~min}$ and a rotation speed of $800 \mathrm{rpm}$. For back-extraction purposes, the stir bars were placed into $250 \mu \mathrm{L}$ glass flat-bottom inserts filled with $200 \mu \mathrm{L}$ of $n$-pentane inside a glass vial. The back-extraction was performed by using ultrasonic treatment and desorption time of $15 \mathrm{~min}$ at constant temperature $\left(25^{\circ} \mathrm{C}\right)$. After back-extraction, the stir bars were removed by means of a magnetic rod and the vials were closed with seals, using a manual crimper, and placed into the automatic liquid sample (ALS) tray for LVI-GC-MS analysis. After each extraction, the stir bars were cleaned to dryness under a stream of purified nitrogen followed by a cleaning with $\mathrm{ACN}$. All the experiments were performed in triplicate.

\subsection{GC-MS analysis}

After sampling the SPME fibre containing the volatile compounds were introduced into the GC injection port at $260^{\circ} \mathrm{C}$ and kept for $6 \mathrm{~min}$ for thermal desorption. Desorbed volatile compounds were separated in an Agilent Technologies 6890 gas chromatograph equipped with a $30 \mathrm{~m} \times 0.25 \mathrm{~mm}$ (i.d.) $\times 0.25 \mu \mathrm{m}$ film thickness TRB-5MS fused silica capillary column (95\% dimethyl, 5\% diphenylpolysiloxane; Teknokroma, Spain), connected to an Agilent 5973N quadrupole mass selective detector (Agilent 7683, Agilent Technologies, Little Falls, DE, USA). The carrier gas used was helium $\mathrm{N} 60$ (Air Liquid, Portugal) at $3.5 \mathrm{~mL} \mathrm{~min}^{-1}$ with a column-head pressure of $21 \mathrm{psi}$ and splitless injections were used (6 min). The GC oven temperature was programmed as follows: initial oven temperature $40^{\circ} \mathrm{C}$, then increased in two steps: $40-175^{\circ} \mathrm{C}$ at $2^{\circ} \mathrm{C} \mathrm{min}^{-1}$ and $175-220^{\circ} \mathrm{C}$ at $10^{\circ} \mathrm{C} \mathrm{min}^{-1}(5 \mathrm{~min})$ in a 77 min running time. The quadrupole operating in electronic ionisation $(70 \mathrm{eV})$ and the acquisition was made in full scan mode (35-550 $\mathrm{m} / \mathrm{z}$ ) using the selected ions illustrated in Table 1 . The quadrupole detector was set as follows: transfer line temperature $280^{\circ} \mathrm{C}$; ion source temperature $230^{\circ} \mathrm{C}$ and quadrupole analyzer temperature $150^{\circ} \mathrm{C}$. The analysis from the SBSE-LD assays were performed using the GC-MS conditions as above with the exception of the inlet port for which an Agilent 7683 ALS and a programme temperature vapourizing (PTV) injector having a baffled liner and a septumless head (SLH; Gerstel, Mülheim a/d Ruhr, Germany) were used. LVI using the solvent vent mode and liquid nitro- 


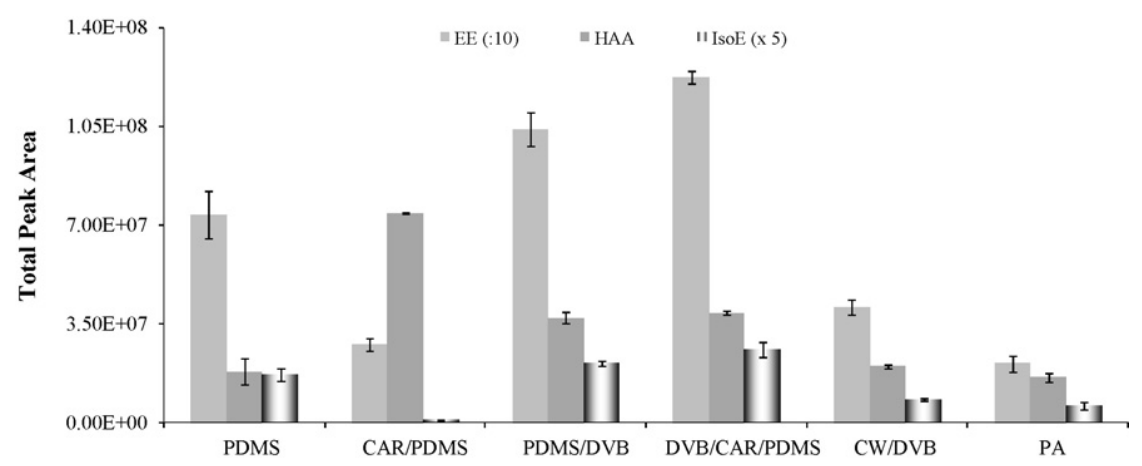

Fig. 1. Influence of the polymeric fibre coating on the HS-SPME yields of higher alcohol acetates (HAA), isoamyl esters (IsoE) and ethyl esters (EE) in wines (other extraction conditions: $60 \mathrm{~min}$ and $25^{\circ} \mathrm{C}$ ).

gen as inlet cooling was operating according to previous work [19]. The solvent vent injection mode was performed (vent time: $0.30 \mathrm{~min}$; flows: $10 \mathrm{~mL} \mathrm{~min}^{-1}$; pressure: 0 psi; purge: $60 \mathrm{~mL} \mathrm{~min}^{-1}$ at $2 \mathrm{~min}$ ), for which the inlet temperature was ramped from $10^{\circ} \mathrm{C}$ $(0.35 \mathrm{~min})$ to $300^{\circ} \mathrm{C}$ at a rate of $600^{\circ} \mathrm{C} \mathrm{min}-1$ and subsequently decreased to $200^{\circ} \mathrm{C}$ (held until end) at a rate of $50^{\circ} \mathrm{C} \mathrm{min}^{-1}$. The injection volume and speed were $20 \mu \mathrm{L}$ and $100 \mathrm{~mL} \mathrm{~min}^{-1}$, respectively.

The mass spectra data were compared with the Wiley library reference spectral bank (G1035B; Rev D.02.00; Agilent Technologies, USA) and confirmed with the retention indices (RI) of standards when they were available. Data recording and instrument control were performed by the MSD ChemStation software (G1701CA; version C.00.00; Agilent Technologies, USA). For the determination of the retention indices (RI) a C8-C20 n-alkanes series was used.

\subsection{Method validation}

Calibration plots constructed using suitable dilution of the global solutions were obtained by the least-square linear regressions of ratio of the peak area of each compound versus the added amount of the targets.

The proposed analytical methods were evaluated in relation to linearity, repeatability (precision, expressed as relative standard deviation (R.S.D.)), evaluation of the recovery of known quantities of substance (accuracy) and detection and quantification limits. The detection (LOD) and quantification (LOQ) limits were calculated as the concentration of the analyte that produce a signal-to-noise ratio of 3 and 10 times, that is $3 S_{y / x} / b$ and $10 S_{y / x} / b$, respectively, where $S_{y / x} / b$ is the blank standard deviation and $b$ is the slope of the regression plot. The linear range experiments provide the essential information to determine the detections and quantifications limits, from lowest concentration point on the linear calibration curve. For recovery studies, ENX wine was spiked with target volatiles and six replicates of the original and spiked wines were assayed (HS-SPME and SBSE-LD) and analysed by GC-MS. The area increments between spiked and original wines were interpolated in the calibration graphs and the experimental concentration calculated. The recovery was determined according to the following relation:

Recovery $(\%)=\frac{C_{1}-C_{0}}{C_{2}} \times 100$

where $C_{0}$ is the concentration in the ENX wine, $C_{1}$ is the concentration found in spiked wine and $C_{2}$ is the concentration added. The repeatability of the method was calculated by six consecutive extractions of the spiked synthetic wines. For each assay the average values and R.S.D. were determined.

\section{Results and discussion}

To compare the performance of both HS-SPME and SBSE-LD analytical methodologies, 15 volatile components were selected as model compounds, i.e. $3 \mathrm{HAA}, 2 \mathrm{IsoE}$ and $10 \mathrm{EE}$ in order to optimise the experimental conditions.

\subsection{HS-SPME optimisation}

In the beginning we investigated for the best fibre coating for HS-SPME, followed by optimisation of the extraction time and temperature, ionic strength and matrix effects, using a constant magnetic stirring $(800 \mathrm{rpm})$. Six types of SPME fibres, differing in the polarity and thickness of the stationary phase, were tested in order to compare their extraction yields towards higher alcohol acetates and esters. The data presented in Fig. 1 showed that the DVB/CAR/PDMS fibre performed the best extraction efficiency for all EE and IsoE. The CAR/PDMS fibre achieved almost two times higher efficiency for acetates than PDMS/DVB and DVB/CAR/PDMS ones, but did not show better extraction efficiency for the ester compounds. On the other hand, the lowest extraction efficiency was obtained by PA. Therefore, the PDMS/CAR/PDMS fibre was selected as the most convenient polymeric phase for HS-SPME analysis of $\mathrm{EE}$ and HAA in commercial wines.

Subsequently, the extraction time profile for the 15 compounds was also performed and the data obtained are depicted in Fig. 2a. Since HS-SPME is a distribution process of the analytes between the wine matrix, vapour phase and polymeric phase (three-phase system), it is very important to establish the most convenient time to reach the equilibrium [30]. In order to investigate the sorption behaviour of wine HAA, IsoE and EE using a DVB/CAR/PDMS fibre, assays were performed at five different extraction times, i.e. 5, 15, 30,60 and $75 \min \left(25^{\circ} \mathrm{C}\right)$. For almost all compounds, the extraction yields increased with time until $60 \mathrm{~min}$. However, after this period, the extraction efficiency decreases slightly due probably to the phenomena competition as this type of fibres present capacity limitations. On the basis of the results obtained, $60 \mathrm{~min}$ of extraction time were selected for further assays.

During HS-SPME analysis, the distribution constant of an analyte between the sample and the fibre coating is influenced very much by the extraction temperature, which depends on the matrix composition and the polymeric phase selected. Since SPME is an exothermic process, when temperature arises the sorption process reduces enhancing HS concentrations but, on the other hand, decreases the partition coefficients due to the thermodynamic effect. According to Carvalho et al. [30], excessive increment of temperature can cause premature desorption of the analytes. Therefore, the effect of temperature on the extraction efficiency was also evaluated by sampling an ENX wine at $25,30,40$ and $60^{\circ} \mathrm{C}$, with the 

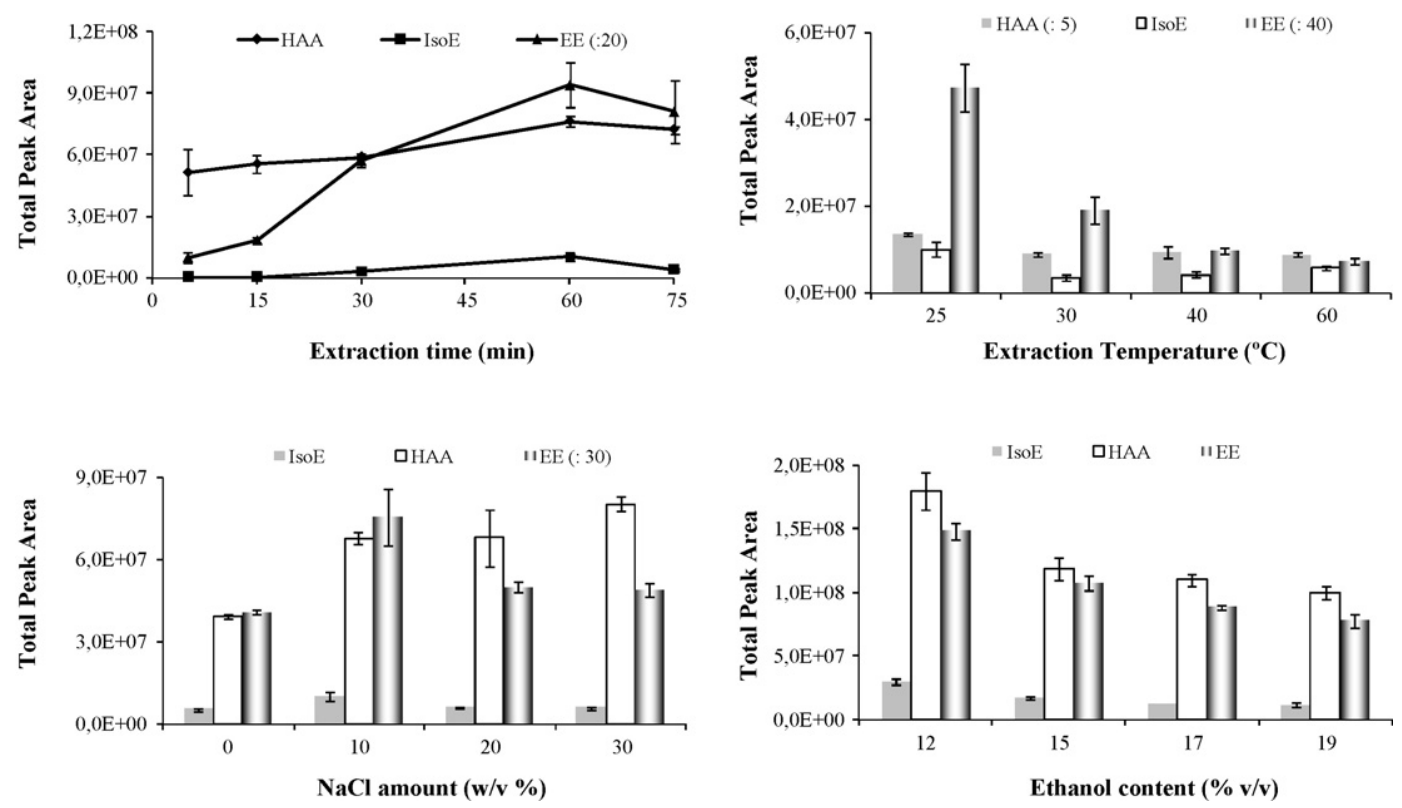

Fig. 2. Influence of the extraction time (a), temperature (b), ionic strength (c) and ethanol content (d) on the extraction efficiency of HAA, IsoE and EE in wines by HS-SPME using a DVB/CAR/PDMS fibre.

DVB/CAR/PDMS fibre incubated for $60 \mathrm{~min}$ (extraction of salt saturated sample: $10 \% \mathrm{NaCl}(\mathrm{w} / \mathrm{v})$ ). As can be observed in Fig. $2 \mathrm{~b}$, the temperature increment leads to a decrease in the extraction yield for the IsoE and EE, although the HAA content increased. As a consequence, $25^{\circ} \mathrm{C}$ was selected for further optimisation. Another parameter that must be taken into consideration is the ionic strength once this greatly influences the partitioning coefficient of the solutes between the liquid and vapour phases. An increment of salt concentration increases the extraction efficiency due to the decrease of analytes solubility, which improves sensi- tivity by promoting higher enrichment into the stationary phase [31]. Thus, the ionic strength was tested at $0,10,20$ and $30 \%$ of $\mathrm{NaCl}(\mathrm{w} / \mathrm{v})$ using the DVB/CAR/PDMS fibre $\left(60 \mathrm{~min}\right.$ at $\left.25^{\circ} \mathrm{C}\right)$ and the results obtained are depicted in Fig. 2c. With the exception of $\mathrm{EE}$ for which better yields were obtained with $10 \%$ of salt, for the remaining chemical families (HAA and IsoE), the analytical response increased with higher salt levels. In general, the addition of $10 \% \mathrm{NaCl}$ promotes the best results and therefore, this amount was chosen to all wine samples prior to analysis. The distribution constant between the polymeric coating and the sample are
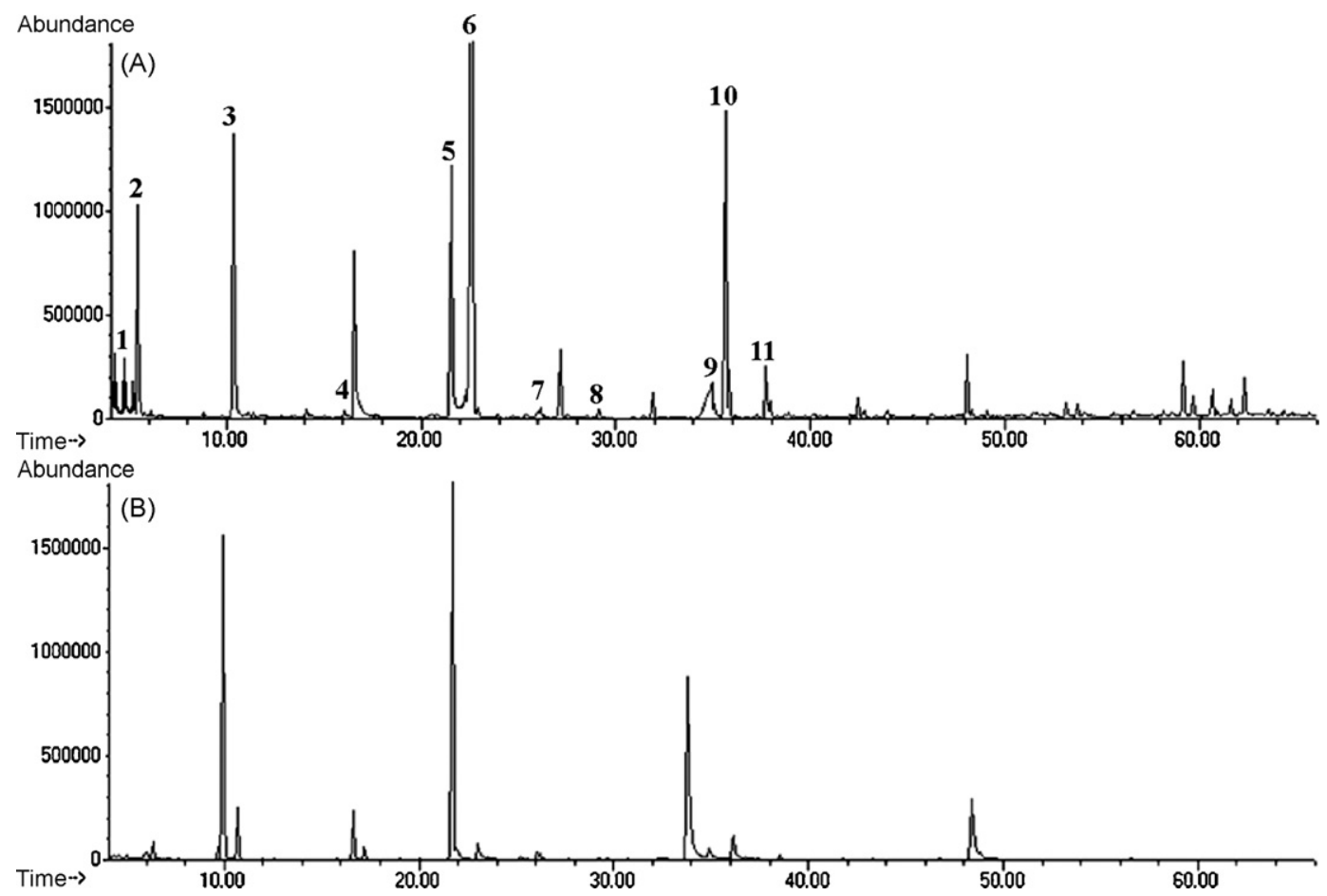

Fig. 3. Typical total ion chromatograms of volatile profiles of COL red wines analysed by (a) SBSE-LD/LVI-GC-qMS and (b) HS-SPME identification: 1: ethyl 2-methylbutanoate + ethyl 3-methylbutanoate; 2: isoamyl acetate; 3: ethyl hexanoate; 4: ethyl heptanoate; 5: diethyl succinate; 6: ethyl octanoate; 7: 2-phenylethyl acetate; 8: ethyl nonanoate; 9: ethyl 9-decenoate + decanoic acid; 10: ethyl decanoate; 11: ethyl succinate. 
Table 2

HS-SPME and SBSE-LD performance characteristics.

\begin{tabular}{|c|c|c|c|c|c|c|c|c|}
\hline \multirow[t]{2}{*}{ Compounds } & \multicolumn{2}{|c|}{$\operatorname{LOD}\left(\mu \mathrm{gL}^{-1}\right)$} & \multicolumn{2}{|c|}{$\operatorname{LOQ}\left(\mu \mathrm{g} \mathrm{L}^{-1}\right)$} & \multicolumn{2}{|c|}{ R.S.D. (\%) } & \multicolumn{2}{|c|}{$\%$ Recovery \pm R.S.D. } \\
\hline & SPME & SBSE & SPME & SBSE & SPME & SBSE & SPME & SBSE \\
\hline \multicolumn{9}{|l|}{ Higher alcohol acetates } \\
\hline Hexyl acetate & 4.35 & 1.16 & 14.49 & 3.87 & 11.02 & 9.05 & $97.04 \pm 6.31$ & $79.07 \pm 5.10$ \\
\hline Ethyl 2-phenyl acetate & 0.42 & 0.07 & 1.41 & 0.22 & 12.41 & 11.74 & $50.09 \pm 9.55$ & $83.91 \pm 9.42$ \\
\hline \multicolumn{9}{|l|}{ Isoamyl esters } \\
\hline Isoamyl acetate & 20.29 & 18.37 & 67.63 & 61.24 & 15.87 & 8.21 & $57.42 \pm 7.87$ & $83.81 \pm 6.66$ \\
\hline Isoamyl hexanoate & 0.02 & 0.10 & 0.06 & 0.34 & 4.10 & 10.31 & $38.43 \pm 9.00$ & $108.04 \pm 10.98$ \\
\hline Isoamyl octanoate & 0.06 & 0.21 & 0.21 & 0.73 & 11.51 & 8.76 & $21.78 \pm 7.12$ & $106.95 \pm 7.75$ \\
\hline \multicolumn{9}{|l|}{ Ethyl esters } \\
\hline Ethyl butanoate & 6.5 & - & 21.6 & - & 9.82 & - & $89.19 \pm 6.63$ & - \\
\hline Ethyl hexanoate & 1.67 & 0.13 & 5.56 & 0.45 & 11.12 & 15.28 & $25.02 \pm 7.47$ & $32.49 \pm 2.45$ \\
\hline Ethyl 2-furoate & 7.91 & 0.53 & 26.38 & 1.75 & 14.03 & 12.03 & $117.27 \pm 5.97$ & $84.08 \pm 6.18$ \\
\hline Ethyl benzoate & 2.61 & 5.56 & 8.71 & 18.53 & 12.76 & 15.51 & $76.87 \pm 7.30$ & $90.79 \pm 5.84$ \\
\hline Ethyl octanoate & 6.12 & 0.20 & 20.39 & 0.67 & 6.98 & 13.76 & $72.09 \pm 6.26$ & $90.38 \pm 7.20$ \\
\hline Ethyl salicylate & 1.71 & 28.96 & 5.68 & 96.56 & 10.59 & 16.52 & $71.12 \pm 9.54$ & $78.02 \pm 4.89$ \\
\hline Ethyl decanoate & 5.60 & 0.07 & 18.69 & 0.23 & 8.70 & 9.79 & $100.38 \pm 13.96$ & $83.91 \pm 9.98$ \\
\hline Ethyl cinnamate & 19.60 & 0.03 & 65.32 & 0.11 & 10.04 & 17.88 & $68.70 \pm 14.59$ & $65.91 \pm 8.59$ \\
\hline Ethyl dodecanoate & 1.46 & 0.23 & 4.87 & 0.77 & 11.78 & 16.24 & $87.87 \pm 13.96$ & $93.60 \pm 11.03$ \\
\hline
\end{tabular}

LOD: limit of detection; LOQ: limit of quantification; R.S.D.: relative standard deviation; (-) not determined by SBSE (solvent delay higher than their retention time).

strongly dependent on the matrix effects. For instance, the ethanol content in wines appears to interfere very much during the HSSPME analytical procedure [23]. Thereby, to check the effect of ethanol content on the HS-SPME extraction yields, four solutions having different contents (12, 15, 17 and 19\% (v/v)) and spiked with the same amounts of volatile compounds were assayed using DVB/CAR/PDMS fibre (extraction of salt sample: $10 \% \mathrm{NaCl}(\mathrm{w} / \mathrm{v})$ during $60 \mathrm{~min}$ at $25^{\circ} \mathrm{C}$ ). Fig. $2 \mathrm{~d}$ compares the data obtained for HAA, IsoE and $\mathrm{EE}$ on that media, where the peak area decreases as the ethanol content increases for all of the studied chemical families. As a consequence no advantages were observed by increasing the ethanolic content.

\subsection{SBSE-LD/LVI optimisation}

By using the SBSE-LD/LVI approach the extraction time, ethanol content, LD conditions and instrumental settings were established, according to a methodology previously optimised [19]. Therefore 10 volatile compounds, representative of the main chemical families of wine, were used, i.e. guaiazulene, $(E, E)$-farnesol, $\beta$-ionone, geranylacetone, ethyl decanoate, $\beta$-citronellol, 2 -phenylethanol, linalool, hexyl acetate and $n$-hexanol were selected for SBSE-LD optimisation. During our assays, stir bars coated with $24 \mu \mathrm{L}$ of PDMS were chosen, once this polymer is the only one commercially available, more effective to non-polar compounds, and needs a low amount of back-extraction solvent $(<200 \mu \mathrm{L})$ inside an insert, which is a key role during the liquid desorption step. The use of a minimum amount of solvent for $L D$ is very convenient since avoid the undesirable solvent evaporation step usually performed for sensitivity enhancement and minimizes possible losses of volatiles. The best solvents used for LD should be the ones that must desorbs the analytes from the PDMS phase and simultaneously present low boiling points for LVI under solvent vent mode avoiding losses of volatiles. For this purposes, several solvents were already tested, namely, ACN, MeOH, $n$-pentane, acetone, diethyl ether, propan-2-ol and azeotropic mixtures. According to the data obtained, $n$-pentane was chosen as the best back-extraction solvent during the LD process, because all standards were detected and the peaks did not present fronting, consequently, more reproducibility was obtained. The time for the back-extraction used was $15 \mathrm{~min}$, since higher period of time did not bring any advantages. For LVI purposes, the chromatographic performance is also very dependent of the He flow rate against solvent used, due to the dependence of the

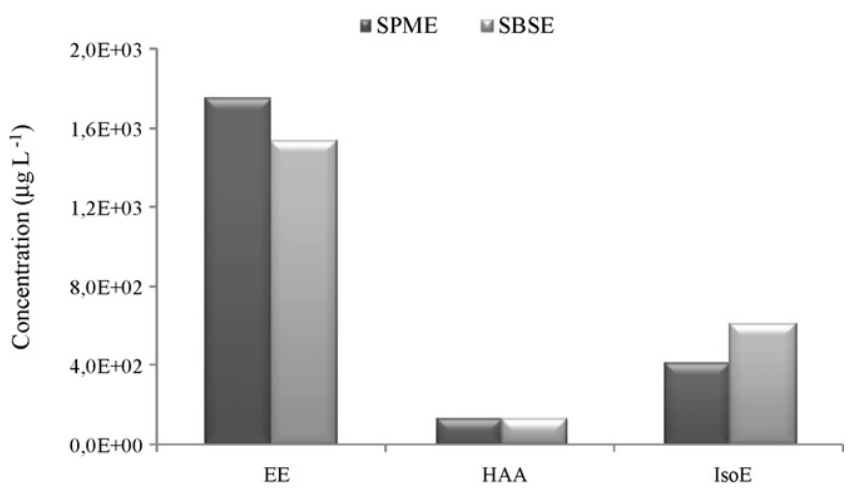

Fig. 4. Comparison of extraction efficiency performance of SBSE and SPME for the analysis of HAA, IsoE and EE.

inlet purge flow rate and temperature in the solvent vent mode. Better performance was observed with flow rate of $10 \mathrm{~mL} \mathrm{~min}^{-1}$ and therefore, was selected as the purge vent. Different inlet purge temperatures were also tested because solvent vent mode is also a critical parameter. According to previous data [19], the recovery of the volatile compounds seems to present higher reproducibility and recovery when the analysis carried out at $10^{\circ} \mathrm{C}$. Since SBSE was used in a two-phase system (liquid sample-stir bar) and is time dependent, we have decided to use $60 \mathrm{~min}$ at $800 \mathrm{rpm}$.

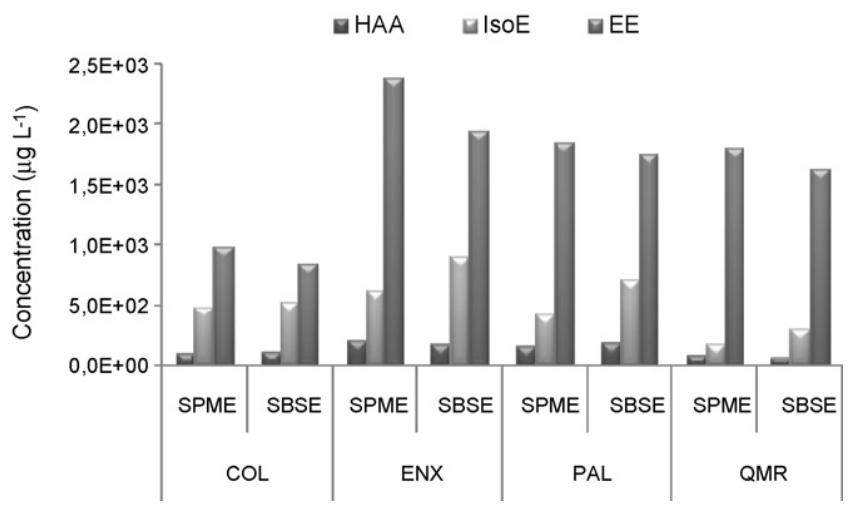

Fig. 5. Concentration of HAA, IsoE and EE. found in commercial wines by HS-

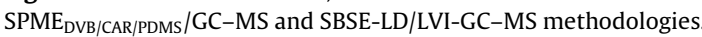


Table 3

Comparison of the SBSE-LD results with those obtained by HS-SPME for higher alcohol acetates, isoamyl esters and ethyl esters found in "Terras Madeirenses" commercial wines

\begin{tabular}{|c|c|c|c|c|c|c|c|c|}
\hline \multirow[t]{3}{*}{ Compounds } & \multicolumn{8}{|c|}{ Concentration $\left(\mu \mathrm{gL}^{-1}\right)$} \\
\hline & \multicolumn{2}{|l|}{$\mathrm{COL}$} & \multicolumn{2}{|l|}{ ENX } & \multicolumn{2}{|l|}{ PAL } & \multicolumn{2}{|l|}{ QMR } \\
\hline & SPME & SBSE & SPME & SBSE & SPME & SBSE & SPME & SBSE \\
\hline \multicolumn{9}{|l|}{ Higher alcohol acetates } \\
\hline Hexyl acetate & $56.26 \pm 0.50$ & $25.43 \pm 0.61$ & $168.98 \pm 10.72$ & $95.14 \pm 4.66$ & $111.17 \pm 5.52$ & $97.57 \pm 3.84$ & $64.93 \pm 5.27$ & $25.35 \pm 1.49$ \\
\hline Ethyl 2-phenyl acetate & $42.08 \pm 3.77$ & $86.13 \pm 12.00$ & $39.42 \pm 5.29$ & $72.98 \pm 15.17$ & $43.59 \pm 2.24$ & $84.08 \pm 13.71$ & $15.35 \pm 0.99$ & $48.37 \pm 4.14$ \\
\hline \multicolumn{9}{|l|}{ Isoamyl esters } \\
\hline Isoamyl acetate & $474.98 \pm 45.63$ & $525.06 \pm 52.99$ & $608.00 \pm 61.29$ & $881.91 \pm 98.62$ & $404.64 \pm 52.70$ & $694.14 \pm 47.71$ & $159.56 \pm 19.06$ & $270.51 \pm 12.21$ \\
\hline Isoamyl hexanoate & $1.09 \pm 0.03$ & $0.25 \pm 0.03$ & $2.67 \pm 0.04$ & $0.93 \pm 0.06$ & $2.57 \pm 0.02$ & $0.91 \pm 0.08$ & $2.56 \pm 0.01$ & $0.45 \pm 0.03$ \\
\hline Isoamyl octanoate & $1.17 \pm 0.04$ & $2.07 \pm 0.14$ & $6.29 \pm 0.04$ & $8.13 \pm 1.65$ & $6.22 \pm 0.03$ & $8.12 \pm 1.08$ & $6.23 \pm 0.01$ & $9.86 \pm 0.87$ \\
\hline Isoamyl decanoate & - & $1.42 \pm 0.56$ & - & $8.72 \pm 0.77$ & - & $8.18 \pm 0.87$ & - & $8.30 \pm 1.15$ \\
\hline \multicolumn{9}{|l|}{ Ethyl esters } \\
\hline Ethyl butanoate & $165.82 \pm 13.52$ & - & $329.25 \pm 41.43$ & - & $211.89 \pm 15.48$ & - & $162.68 \pm 10.24$ & - \\
\hline Ethyl 2-methylbutanoate & - & $3.95 \pm 0.50$ & - & $1.67 \pm 0.13$ & - & $1.97 \pm 0.28$ & - & $2.11 \pm 0.15$ \\
\hline Ethyl 3-methylbutanoate & $3.54 \pm 0.41$ & $1.63 \pm 0.43$ & $1.87 \pm 0.38$ & $0.68 \pm 0.22$ & $1.41 \pm 0.61$ & $0.75 \pm 0.14$ & $3.15 \pm 0.92$ & $3.01 \pm 0.36$ \\
\hline Ethyl hexanoate & $118.43 \pm 25.66$ & $160.44 \pm 5.04$ & $316.95 \pm 45.94$ & $338.43 \pm 29.68$ & $263.03 \pm 21.45$ & $288.76 \pm 10.26$ & $219.10 \pm 51.82$ & $246.66 \pm 27.09$ \\
\hline Ethyl 2-hexenoate & - & $1.52 \pm 0.05$ & - & $1.54 \pm 0.06$ & - & $2.10 \pm 0.04$ & - & $2.07 \pm 0.11$ \\
\hline Ethyl heptanoate & - & $2.73 \pm 0.07$ & - & $1.73 \pm 0.05$ & - & $1.81 \pm 0.03$ & - & $2.11 \pm 0.13$ \\
\hline Methyl octanoate & $1.93 \pm 0.88$ & $0.35 \pm 0.02$ & $2.01 \pm 0.12$ & $0.58 \pm 0.06$ & $1.46 \pm 0.06$ & $0.48 \pm 0.02$ & $1.45 \pm 0.21$ & $0.33 \pm 0.07$ \\
\hline Diethyl succinate & $163.47 \pm 19.87$ & $112.77 \pm 8.19$ & $125.87 \pm 8.21$ & $46.37 \pm 5.66$ & $116.36 \pm 7.29$ & $70.16 \pm 6.32$ & $209.32 \pm 32.88$ & $100.58 \pm 4.89$ \\
\hline Ethyl octanoate & $381.21 \pm 20.39$ & $351.37 \pm 22.92$ & $915.83 \pm 83.07$ & $943.47 \pm 76.25$ & $804.57 \pm 34.48$ & $866.90 \pm 7.07$ & $744.68 \pm 36.71$ & $813.13 \pm 9.36$ \\
\hline Ethyl phenylacetate & - & $48.69 \pm 2.75$ & - & $22.53 \pm 0.52$ & - & $26.63 \pm 0.74$ & - & $39.74 \pm 0.92$ \\
\hline Ethyl nonoate & $2.57 \pm 0.13$ & $0.49 \pm 0.04$ & $1.54 \pm 0.06$ & $0.31 \pm 0.12$ & $1.44 \pm 0.07$ & $0.28 \pm 0.04$ & $1.48 \pm 0.03$ & $1.48 \pm 0.08$ \\
\hline Methyl decanoate & - & $9.94 \pm 0.02$ & - & $9.86 \pm 0.02$ & - & $9.74 \pm 0.02$ & - & $9.63 \pm 0.03$ \\
\hline 2-Methylpropyl octanoate & $14.73 \pm 1.04$ & $9.40 \pm 0.00$ & $38.77 \pm 6.05$ & $25.55 \pm 0.01$ & $28.64 \pm 2.05$ & $19.50 \pm 0.01$ & $16.74 \pm 1.05$ & $16.51 \pm 0.02$ \\
\hline Ethyl 9-decenoate & $1.44 \pm 0.15$ & $1.72 \pm 0.09$ & $4.78 \pm 0.66$ & $1.76 \pm 0.09$ & $9.81 \pm 0.78$ & $3.48 \pm 0.26$ & $1.81 \pm 0.40$ & $1.76 \pm 0.07$ \\
\hline Ethyl decanoate & $110.27 \pm 17.83$ & $61.43 \pm 2.04$ & $630.94 \pm 67.39$ & $457.43 \pm 18.94$ & $391.55 \pm 24.23$ & $371.95 \pm 16.74$ & $422.11 \pm 12.69$ & $355.42 \pm 45.30$ \\
\hline Ethyl succinate & - & $20.61 \pm 0.12$ & - & $36.21 \pm 0.04$ & - & $51.55 \pm 0.06$ & - & $14.64 \pm 0.02$ \\
\hline Ethyl 3-hydroxyoctanoate & - & $1.57 \pm 0.12$ & - & $4.15 \pm 0.48$ & - & $2.83 \pm 0.13$ & - & $2.26 \pm 0.11$ \\
\hline Ethyl dodecanoate & $9.96 \pm 0.02$ & $3.11 \pm 0.02$ & $21.72 \pm 0.62$ & $27.09 \pm 1.27$ & $19.77 \pm 0.75$ & $13.95 \pm 0.75$ & $17.40 \pm 0.12$ & $10.02 \pm 0.86$ \\
\hline Butyl hexadecanoate & - & $14.54 \pm 1.90$ & - & $4.38 \pm 0.75$ & - & $6.46 \pm 0.91$ & - & $3.38 \pm 0.14$ \\
\hline Butyl octadecanoate & - & $34.88 \pm 5.81$ & - & $22.98 \pm 3.77$ & - & $8.83 \pm 0.83$ & - & $1.70 \pm 0.44$ \\
\hline
\end{tabular}


Fig. 3 compares total ion chromatograms of wine samples obtained

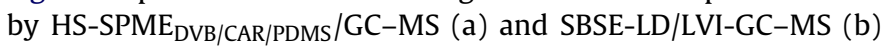
methodologies, under optimised experimental conditions. As it can be observed, both methods present good performance besides the latter approach showed much better overall sensitivity in particular to detect minor constituents.

\subsection{Validation and comparison of SPME and SBSE methodologies}

In a first approach, both methodologies are very easy to workup without special instrumental needs, which make them potential analytical tools to analyse wines in any conventional laboratory. Although SBSE-LD presents a much higher capacity and therefore better sensitivity than HS-SPME, the selectivity concerning the polar characteristics of the analytes under study, seems to be better performed by the latter since we have the possibility to choose the more suitable polymeric phase and in the former case, only PDMS is available. In the experimental point of view, SBSE-LD is a technique much more robust than HS-SPME, without any polymeric damage during analytical manipulation, do not need salt addition to increase the vapour tension or suitable temperature control and if the right desorption solvent is combined with LVI, present a remarkable performance as it was successfully demonstrated to the particular case of acetates and esters in wines.

In Tables 1 and 2, the calibration parameters (linearity, repeatability (precision, expressed as R.S.D.), recovery of known quantities of substance (accuracy), LODs and LOQs, are given for both methodologies. Calibration plots constructed using suitable dilutions of the global solutions were obtained by the least-square linear regressions of ratio of the peak area of each compound versus the added amount of the targets. Both methodologies showed good linearity over the concentration ranges tested with all determination coefficients $\left(r^{2}\right)$ higher than 0.982 . Regarding the detection purposes, some differences were observed between both analytical approaches since ethyl lactate and ethyl butanoate were not found by SBSE-LD. Detection and quantification limits (Table 2) were achieved by extrapolation of the lowest concentrations points from the standard plots ( 3 and 10 times the R.S.D. of blanks, respectively). Therefore, LODs ranged between $0.02 \mu \mathrm{g} \mathrm{L}^{-1}$ (isoamyl hexanoate) and $20.29 \mu \mathrm{g} \mathrm{L}^{-1}$ (isoamyl acetate) were found for HSSPME methodology, whereas for SBSE-LD ranged from $0.03 \mu \mathrm{g} \mathrm{L}^{-1}$ (ethyl cinnamate) to $28.96 \mu \mathrm{g} \mathrm{L}^{-1}$ (ethyl salicylate). In average the LOD's values obtained by SBSE-LD were lower than those obtained by HS-SPME. LOQs ranged from $0.06 \mu \mathrm{g} \mathrm{L}^{-1}$ (isoamyl hexanoate) to $67.63 \mu \mathrm{g} \mathrm{L}^{-1}$ (isoamyl acetate) and $0.11 \mu \mathrm{g} \mathrm{L}^{-1}$ (ethyl cinnamate) to $96.56 \mu \mathrm{gL}^{-1}$ (ethyl salicylate) for HS-SPME and SBSE-LD, respectively. The repeatability has been evaluated by means of a series of six extractions from the same wine. The results indicated that the methods had good repeatability. For HS-SPME good within-day precision was noticed with R.S.D. values between $4.10 \%$ (isoamyl hexanoate) and $15.87 \%$ (isoamyl acetate). For SBSE-LD methodology the R.S.D. values ranges between $8.21 \%$ (isoamyl acetate) and $17.88 \%$ (ethyl cinamate). In order to check the accuracy of the proposed methods, a recovery study was carried out by fortifying an ENX wine sample. For HS-SPME approach, the recoveries of the higher alcohol acetates, isoamyl esters and ethyl esters from spiked samples varied from $21.78 \%$ (isoamyl octanoate) to $117.27 \%$ (ethyl 2 -furoate) with an average recovery of $69 \pm 8 \%$, while by using SBSE-LD approach the recoveries ranging between $32.49 \%$ (ethyl hexanoate) to $108.04 \%$ (isoamyl hexanoate) with an average of $81 \pm 8 \%$. These results corroborate the higher accuracy of SBSE.

\subsection{SBSE and SPME application to wines}

Six samples of each wine (one red and three white wine) were analysed by SBSE and SPME methodologies under optimised condi- tions. As expected, the recovery of EE depends on the enrichment methodology used. Qualitative and quantitative differences were definitely observed in the chromatographic profiles obtained by both approaches (Fig. 3). A higher number of HAA, IsoE and EE were detected in the sample studied by means of SBSE. A total of 25 target compounds were identified and quantified from the analysed wines by SBSE-LD/LVI-GC-qMS, while by HS-SPME/GC-qMS only 16 compounds were identified. The compounds included $20 \mathrm{EE}, 2$ HAA and 4 IsoE. The results obtained for these samples are shown in Table 3. SBSE-LD/LVI-GC-MS provided higher efficiency in the extraction of HAA (31.1\%) and IsoE (1.2\%) than HS-SPME/GC-MS (21.6\% and $0.3 \%$, respectively). The latter methodology showed a better efficiency extraction of $\mathrm{EE}$ (78.2\%) than the former (67.7\%). This analysis allows the conclusion that the SBSE-LD approach is generally a more sensitive methodology than HS-SPME in extracting these chemical classes of volatile compounds (Fig. 4). However, these methodologies can be complementary because some volatile compounds with low $\log K_{\mathrm{O} / \mathrm{W}}$ values (ethyl butanoate) are not detected by SBSE-LD.

Among HAA, isoamyl acetate highlighted with their higher concentrations. Hexyl acetate and 2-phenylethyl acetate were found as well, but at lower amounts. As can be seen (Table 3), SBSE-LD exhibits better sensitivities than HS-SPME for IsoE and 2-phenylethyl acetate. However, hexyl acetate shows better extraction efficiency by HS-SPME than that SBSE-LD. According to their mean contents (Fig. 5), the ENX, PAL and COL wines had higher concentrations (559.40-816.40 $\mu \mathrm{g} \mathrm{L}^{-1}$ (HS-SPME) and 636.62-1050.03 $\mu \mathrm{g} \mathrm{L}^{-1}$ (SBSE-LD) than QMR wines $\left(239.84 \mu \mathrm{g} \mathrm{L}^{-1}\right.$ (HS-SPME) and $328.23 \mu \mathrm{g} \mathrm{L}^{-1}$ (SBSE-LD)). In general, these compounds are responsible for the "fruity" and "floral" characteristics of young wines.

The fatty acids EE are produced enzymatically during yeast fermentation from ethanolysis of acylCoA which is formed from fatty acids synthesis or degradation. Their concentration is dependent on several factors mainly: yeast strain, fermentation temperature, aeration degree and sugar contents. Among the EE identified, the major compounds were, ethyl octanoate, ethyl hexanoate and ethyl decanoate. HS-SPME showed higher sensitivities for this chemical group than SBSE-LD approach.

As can be seen in Table 3, SBSE-LD exhibits better sensitivities than HS-SPME for IsoE. It has been observed that their mean values were very similar and they did not present significant differences between ENX, PAL and QMR wines using HS-SPME and SBSE-LD approaches. The COL wine presents the lowest concentration of IsoE, namely 2.26 and $3.74 \mu \mathrm{g} \mathrm{L}^{-1}$ for HS-SPME and SBSE-LD methods, respectively. Among the identified IsoE, the isoamyl octanoate were at higher concentrations in the four types of wines.

\section{Conclusions}

HAA, IsoE and EE of red and white commercial wines extracted using the two analytical methods headspace solid-phase microextraction and stir bar sorptive extraction-liquid desorption, were determined by GC-MS. These methodologies are sensitive, fast, easy, reliable, solventless techniques and an alternative to the traditional methods to characterize volatiles in wines.

The SBSE-LD method showed higher sensitivity than HS-SPME for the selected volatile compounds. Twenty-five esters were identified by SBSE-LD using $n$-pentane as solvent back-extraction whereas only 16 esters were identified by the HS-SPME method.

Both analytical methods showed good linearity, precision, detection and quantification limits that allow their application in real samples. Quantitatively, EE of fatty acids, namely ethyl hexanoate, octanoate and decanoate were the major volatile compounds found in studied wines. Their concentration, higher than LPO, enables their contribution to wine sensory proprieties with 
"fruit" and "cheese/fatty" odours. Both approaches are highly sensitive and can be applied to a wide variety of food matrices.

\section{Acknowledgments}

The authors are grateful to the Interreg IIIB-MAC and FEDER, for the financial support provided to ANTIVINMAC 05/MAC/2.3/M28 Project.

\section{References}

[1] S.M. Rocha, P. Coutinho, I. Delgadillo, M.A. Coimbra, J. Chromatogr. A 1150 (2007) 155.

[2] J.S. Câmara, P. Herbert, J.C. Marques, M.A. Alves, Anal. Chim. Acta 513 (2004) 203.

[3] D. Komes, D. Ulrich, T. Lovric, Eur. Food Res. Technol. 222 (2006) 1.

[4] R. Perestrelo, A. Fernandes, F.F. Albuquerque, J.C. Marques, J.S. Câmara, Anal. Chim. Acta 563 (2006) 154.

[5] Y. Kotseridis, R. Baumes, J. Agric. Food Chem. 48 (2000) 400.

[6] A. Rapp, H. Mandery, Experientia 43 (1986) 873.

[7] J.C.R. Demyttenaere, J.I.S. Martínez, R. Verhé, P. Sandra, N. Kimpe, J. Chromatogr A 985 (2003) 221.

[8] J.S. Câmara, J.C. Marques, R.M. Perestrelo, F. Rodrigues, L. Oliveira, P. Andrade, M. Caldeira, J. Chromatogr. A 1150 (2007) 198.

[9] W.Wardencki, J. Curylo, J. Namiesnik, J. Biochem. Biophys. Meth. 70 (2007) 275

[10] M. Liu, Z. Zeng, Y. Tian, Anal. Chim. Acta 540 (2005) 341.
[11] M. Shimoda, T. Shibamoto, A.C. Noble, J. Agric. Food Chem. 41 (1993) 1664.

[12] P. Karásek, J. Planeta, E.V. Ostrá, M. Mikesová, J. Golias, M. Roth, J. Vejrosta, J. Chromatogr. A 1002 (2003) 13.

[13] G. Giraudi, L. Anfossi, C. Baggiani, C. Giovannoli, C. Tozzi, J. Chromatogr. A 1175 (2007) 174.

[14] S. Cabredo-Pinillos, T. Cedrón-Fernández, M. González-Briongos, L. PuentePascual, C. Sáenz-Barrio, Talanta 69 (2006) 1123.

[15] H. Lord, J. Pawliszyn, J. Chromatogr. A 885 (2000) 1531.

[16] L. Arthur, J. Pawliszyn, Anal. Chem. 62 (1990) 2145.

[17] E. Baltussen, P. Sandra, F. David, C. Cramers, J. Microcol. Sep. 11 (1999) 737.

[18] R.F. Alves, A.M.D. Nascimento, J.M.F. Nogueira, Anal. Chim. Acta 546 (2005) 11

[19] E. Coelho, R. Perestrelo, N.R. Neng, J.S. Câmara, M.A. Coimbra, J.M.F. Nogueira, S.M. Rocha, Anal. Chim. Acta 624 (2008) 79.

[20] P. Serôdio, J.M.F. Nogueira, Anal. Chim. Acta 517 (2004) 21.

[21] P. Serôdio, M.S. Cabral, J.M.F. Nogueira, J. Chromatogr. A 1141 (2007) 259.

[22] A. Zalacain, J. Marín, G.L. Alonso, M.R. Salina, Talanta 71 (2007) 1610.

[23] F. Rodrigues, M. Caldeira, J.S. Câmara, Anal. Chim. Acta 609 (2008) 82.

24] C. Dietz, J. Sanz, C. Cámara, J. Chromatogr. A 1103 (2006) 183.

[25] F. David, P. Sandra, J. Chromatogr. A 1152 (2007) 54.

[26] A.R.M. Silva, F.C.M. Portugal, J.M.F. Nogueira, J. Chromatogr. A 1209 (2008) 10-16.

[27] E. Coelho, M.A. Coimbra, J.M.F. Nogueira, S.M. Rocha, Anal. Chim. Acta 635 (2009) 214.

[28] R. Perestrelo, M. Caldeira, F. Rodrigues, J.S. Câmara, J. Sep. Sci. 31 (2008) 1841

[29] L. Ferreira, R. Perestrelo, J.S. Câmara, Talanta 77 (2009) 1087.

[30] P.N. Carvalho, L.F. Pinto, M.C.P. Basto, M.T.S.D. Vasconcelos, J. Microchem. 87 (2007) 147.

[31] C. Pizarro, N. Pérez-del-Notario, J.M. González-Sáiz, J. Chromatogr. A 1143 (2007) 26. 